\title{
Implementation of Digital Economy in Russia's Banking Business Using the Experience of Other Countries
}

\author{
Vera Stepanova ${ }^{1, *}$ \\ ${ }^{1}$ Togliatti State University, Togliatti 445020, Russian Federation \\ *Corresponding author. Email: lawboxer@gmail.com
}

\begin{abstract}
The objective of this paper is to identify the level of compliance of digitalization of Russia's banking business-sector with European standards and requirements. In the course of the study, the overall degree of readiness for the development of the digital economy in Russia will be evaluated through an analysis of the degree of maturity of information and communication technologies that are actively being introduced into the economic sector. The methodological study is based on the conceptual principles that characterize the post-industrial theory of society development specifically in the context of digitalization of the economic activity of state. General methods of induction and deduction, a comparative analysis of expert estimates, analytics of statistical data and the general systematization of the information received were applied in the study. Above all, with the active transition to digital economy, economic security of the financial sector must become one of the strategic areas of development. The article analyses factors and risks, as well as the prospects for the development and implementation of digitalization in the banking business of Russia using the experience of foreign countries.
\end{abstract}

Keywords: Economy digitalization, Internet banking, banking sector, Digital-channel, banking system management, decentralization of cryptographic systems, AMCS, biometric system.

\section{INTRODUCTION}

World statistics show that the content of the share of the digital economy in the structure of Russia's total GDP in 2015-2018 is significantly lower than the level of the world's leading countries, and therefore there is an objective need for a targeted increase in indicators in this matter.

First of all, it was necessary to organize the work on improvement of the level of the state legal field - to develop a series of legislative acts aimed at implementation and systematically phasing of digitalization of the state economy according to the scheme proposed by Bell back in 1973, when he listed the main factors reflecting post-industrial society [1]. A number of such documents have already been put into effect, thereby actively implementing and expanding the boundaries of the country's economy digitalization. For example, the Special Federal Program "Electronic Russia" (Decree No. 65 of January 28, 2002) [2], which was in force during 2002-2010 and was aimed at the formation of e-state and e-government; or The Strategy for the Development of the Information Society in the Russian Federation for 2017-2030 (Decree of the President of the Russian Federation of May 9, 2017 No. 203) [3]; Government program "Digital Economy of the Russian Federation" (Order of the Government of the Russian Federation of July 28, 2017 No. 1632-p) [4]; "On National Goals and Strategic Objectives of the Russian Federation through to 2024" (Decree of the
President of the Russian Federation of May 7, 2018, also known as the second May Decree of the President of the country) [5]. Digitalization of the Russian economy may result in banks stop being the flagships that shape its economy. The study by McKinsey analytical agency made within the program "Innovation in Russia is an inexhaustible source of growth", the active digitalization of the banking sector will be completed by 2030, which will lead to optimization of banking activities in various fields of business activities, of the sphere of interaction between banks and customers, as well as of industry as a whole [6]. The objective of the strategy is to create the conditions for the formation of a knowledge society in Russia.

The rest of the paper is organized as follows. The first part describes the general issues related to the stated topic of the study. Problem issues are identified, statistical data are given, arguments are given that for the banking sector of the economy for the banking sector of the economy, digital transformation is concluded in five stages. Further, in the second section, the specifics of Russian digital banking are analysed and conclusions are made about the features of the formation of the digitalization banking environment in Russia. In conclusion, general conclusions are made.

\section{LITERATURE REVIEW}

According to the generation type of assumptions, we divided the existed work into two categories. 


\subsection{Manual interactive assumption generation}

Among the priorities is the formation of the information space, taking into account the needs for high quality and reliable information; creation and implementation of Russian information and communication technologies, ensuring their competitiveness at the international level; the need to safeguard national interests in the sphere of digital economy.

At the international level, it is necessary to create new mechanisms for partnership in order to develop a system of trust on the Internet, to guarantee the confidentiality and personal safety of users, and to eliminate the anonymity, irresponsibility of users and impunity of offenders.

The main way to ensure the effectiveness of the digital economy is the introduction of data processing technology, which will reduce costs in the production of goods and services.

The states with economic sectors based on technologies for analysis of large volumes of data have competitive advantage in the world market. Such technologies are actively used in Russia, but they are based on foreign developments.

Currently, there are no domestic analogues. The widespread introduction of foreign information and communication technologies, including those at critical information infrastructure facilities, complicates the challenge to protect the interests of citizens and the state in the information sphere. The Internet is increasingly becoming the source of computer attacks on public and private information resources and on objects of critical information infrastructure.

The pace of technology development, creation, processing and dissemination of information significantly exceeded the capabilities of most people in the development and application of knowledge. The change in emphasis in the worldview, especially on the Internet, from scientific, educational and cultural to entertaining and reference formed a new model of perception - the so-called mosaic thinking, which is characterized by a mass surface perception of information. This form of information acquisition makes it simpler to impact on people's views and preferences, contributes to the formation of imposed behaviours, which gives an advantage in achieving economic and political goals to those states and organizations that own information dissemination technologies.

International legal mechanisms to defend the sovereign right of states to regulate the information space, including in the national segment of the Internet, have not been established. Most states are forced to adapt their state regulation of information and information technology to new circumstances "on the fly".

\subsection{Learning-based assumption generation}

For example, McKinsey analysts are confident that the ongoing implementation of advanced economy digitalization technologies in the banking business of Russia will optimize, that is, it will reduce bank expenditures by at least $15 \%$, and in long-term forecasts this figure should aim at $60 \%$ at the completion stage. Digitalization of the banking business will make it possible to collect more accurate customer data in the process of collecting and accumulating customer information when issuing a loan, and will reduce the risks of banks and increase their share of income.

In addition to direct banking services, the field of secondary, non-banking services, such as the development and implementation of common security systems, insurance, transaction support, actively develops. One of the examples is the widely used function of integrating access control systems (ACS) into debit cards of Sberbank with PayPass technology. The point is that the employee's salary card can simultaneously perform the pass function. Experimental implementation of this system has already been carried at certain constituent entities of the Russian Federation since 2015, and starting from 2018, the wide-spread implementation of this product began.

It should be noted that today PJSC Sberbank is the largest bank in Russia and one of the leading global financial institutions, which accounts for one third of the assets of the entire Russian banking sector. Sberbank is a key creditor for the national economy and it holds the largest share in the deposit market. The founder and main shareholder of PJSC Sberbank is the Central Bank of the Russian Federation, which owns $50 \%$ of the authorized capital stock plus one voting share. The other half of the shares belong not only to Russian, but also to international investors, which also increases their value in the global economic sector. Sberbank's services are in demand by more than 135 million individuals and more than 1 million legal entities in 22 countries, which makes Sberbank the most extensive branch network both in Russia and abroad. Currently, Sberbank is a network consisting of a large number of subsidiary banks and branches, the total number of which is about 17 thousand branches and in-structural units in the UK, USA, CIS, Central and Eastern Europe, Turkey and other countries.

With implementation of integration product for access control system, PJSC Sberabank simultaneously solves the issues in three strategic areas of economic sector development: it increases the security level in the banking business, provides easier access to its products, taking care of customers by combining several functions in one product, in this case, in a debit card. It also actively integrates the bank in other industries, since enterprises, by concluding agreements on usage of the 
access control system with the bank, immediately receive concentrated information about their employees and almost complete control of their personal data and access to them.

These trends in development and digitalization are observed in all major banking organizations of the country. For example, since the beginning of 2019, VTB has also started to collect customer data within the creation of a unified biometric system. This work was entrusted to the ITeko Innovation Center, which began active work in the second half of 2018 .

\subsection{Assumption generation based on abstraction-refinement}

Currently, after a long phase of stagnation, which began in 2015 and was preceded by one of the most severe economic crises of 2008, the Russian banking business actively develops and introduces advanced digitalization technologies. Along with the vigorous growth of activity, new entities in this sphere are being introduced in the banking business; these are the various so-called "neo-banks" that profit from small banking services, mainly commissions for various banking transactions, and non-banking organizations that are actively interact with it. At the same time, the very structure of banking is changing, with extension of the scope of its services and changes in its competitiveness and stability. Today, traditional banking reduces its profitability, and is being replaced by Internet banking, digitalization of general banking and the search for other sources of income by the bank. The two most perspective directions in this process are new banking products based on digital technologies and non-banking products created in partnership with third-party firms [7].

The above-mentioned crisis shocks prompted the active complication of the banking business and its entire infrastructure, a series of mergers and acquisitions among banks.

Analysts found that specifically for the banking sector of the economy, digital transformation has five stages:

1. The approval and creation of the Digital channel proper: the introduction of an ATM network, Internet banking and mobile applications. At the center of this block of changes is the end user himself as the consumer of banking services, who gets the most favorable conditions for accessing the bank at any convenient time and in any convenient way.

2. Active development of Digital products: development of contactless payment system, the issue of virtual cards with an interface based on artificial intelligence and the possibility of machine learning.
Recent scientific developments in this area enable creation of products in E2E (end to end) style with the main task to satisfy customers' financial needs 24 hours a day [8].

3. The combination of all elements in a single digital service cycle. At this stage, most Russian banks not only have to be equipped with the ability to use Digital services, but also actively introduce them into the customer service and management systems, what requires complete review of the business model of the banking environment.

4. Active implementation and use of Digital tools will enable the bank to operate on a global level beyond the borders of states and distances. The next stage after the globalization of Digital tools should be the creation of a global Digital Brain. Its purpose will be the automated and continuous online collection of data on all banking sectors, analysis and identification of weaknesses of the working network, followed by the transfer of information to the appropriate service centers.

5. The result of all development should be the creation of the so-called "digital DNA" - an automated debugged program that could guide and coordinate the entire cycle of the bank's activities in all areas.

Thus, at present, the digital transformation of the entire industry of Russian banks has served as a good basis for the development of digitalization of banking activities and the expansion of the range of banking products through remote service channels. For example, according to the Burnmark Research Center, the use of mobile applications by Russians has grown from $22 \%$ in 2011 to $46 \%$ in 2018 and continues to grow rapidly [9]. Thus, by the end of 2018, Russia entered the top 5 countries in Europe in the development of digital banking, and the mobile applications of Russian banks have in their arsenal a much wider range of functions than their analogues of European banks.

\section{MATERIALS AND METHODS}

In the modern banking business, leaders should be focused on three main areas of business development, namely, customer experience, operational processes and modern business models. According to the IDC research group forecast, by the end of 2019, three-quarters of the participants in the Global 2000 list have already approved the digital transformation as the basis for their corporate development strategy.

A specific feature of Russian digital banking is its high competitiveness, which enable users to easily change and search for a bank based on their specific needs. The advantage in this case will be the undeniable continuous development of banking systems in the race for customer. There are no so many competing banks in 
the EU, and existing ones tend to adhere to conservative traditions of operation. In this situation, Russia has a clear advantage: in this case, Russian digital equipment will be much younger and more promising than abroad. In addition, Russia is also the largest platform for the development of the Internet market, and, accordingly, the net of Internet banking and mobile banking services.

The basic need that is covered during the development of innovative technologies and digitalization of the banking business in Russia is the creation of publicly available, simple products that will most closely meet the needs of the end customer. This problem can be solved by directing significant resources for the analysis of large amounts of data, for a deeper study of the issue using artificial intelligence, as well as for machine testing of the results obtained [10]. For example, "robotic advising" and "blockchain" allow to carry out the vast majority of operations without intermediaries.

The example of the final work products created with these technologies can be an online service of a mortgage broker from Tinkoff Bank or user identification with their photographs for transfers at Bank "Otkrytie". In addition, the increasingly popular access control system, ACS, will continue to increase its operational efficiency by accumulating databases of biometric identification systems not only for customer identification, but also for remote conclusion of contracts with customers.

Russian banks are successfully mastering the blockchain technology. For example, Rosevrobank in partnership with Microsoft, based on the Ethereum Consortium Blockchain infrastructure, proposed client identification through applications by any other bank that exchanges data with Rosevrobank to determine the status and to identify the client. Thus, the client has the possibility to receive services from different banks in one place (in one application) on the principle of a single window.

The Central Bank of Russia is testing a new "Masterchain" software package based on the Microsoft Ethereum Consortium Blockchain. It is based on blockchain technology for storage and exchange of information on transactions. Masterchain will become an integration platform on the infrastructure of the Central Bank of the Russian Federation, with Russian banks as distributed nodes of it. The system will allow the integration of various blockchain and payment systems. The system will provide the environment of digital trust for banks participating in data exchange. Blockchains store data in a hashed (encrypted) form, so none of the participating bank violates the law on access to client's personal data. At the same time, Masterchain enables identification management, simplification of arbitration and acceleration of mutual settlements. The banking community will be able to join forces to develop new fast and efficient services for customers, who seek to use the resources of several banks simultaneously. Sberbank of
Russia is testing the system of electronic workflows with an electronic digital signature, based on blockchain technology. In 2016, Alfa-Bank became the first in Russia to conclude a letter of credit transaction with S7 Airlines using smart contract technology based on blockchain. Alfa-Bank also participates in the Masterchain system. All stages of the transaction between S7 Airlines as the customer and the contractor who worked with the company were secured by the bank. The transfer of money from the customer to the contractor's account also was performed based on the execution and verification of the blockchain transaction to provide data from the contractor to the customer; the results of the transaction were recorded in a blockchain in a hashed (encrypted) form. Thus, openness and transparency, as well as the speed of transactions of any complexity at all the stages, increase; the trust among parties and to the bank as a guarantor of the transaction increases. In the future, any counterparties can substantially reduce costs on the processes of preparation and implementation of complex transactions through the control and interaction of smart contracts operating on a blockchain platform, with a bank ensuring its credibility and as the guarantor of transactions.

Another area that is gaining wide popularity is cashback services. Besides having mainly personalized nature, they also enable the owner to choose a specific category of purchases that will be taken into account for creation of individual offers. Thus, direct interaction with clients drops practically to zero, with the first place taken by systems for automated collection and analysis of data, which flow to a common analytical center, which, in turn, can generate statistical data for completely different requests practically without human intervention and issue a machine-made complete analytical review.

The Central Bank of the Russian Federation also takes an active part in the digitalization of the banking business. For example, in 2016, it initiated the creation of the FinTech Association, which allowed the development and implementation of quick payment system for instantly transfer of money between banks by phone number.

In 2016, MTS provided its customers with the ability to download virtual bank cards, travel tickets and discount coupons to smartphones using the MTS Money application. Later, jointly with MTS Bank, they introduced Samsung Pay and Apple Pay services in Russia. At the same time, the operator's solution is available not only to owners of premium smartphones, but also to owners of most other smartphones that support NFC technology for contactless payment.

An important factor in the information development and general digitalization of the banking business is the interaction with technology companies that jointly develop and implement innovative solutions through outsourcing of innovations and other forms of 
cooperation. For example, strategically important partners for banks can be the so-called "user information aggregators", primarily, social networks and communications providers that have access to external data about potential and existing customers.

\section{PROBABILISTIC AUTOMATA}

For a long time, the digitalization of the banking business and of the Russian economy as a whole was hindered by conservative laws in the areas of security of personal data circulation and processing in terms of remote identification: it was forbidden to open deposits without a passport and personal presence at the legislative level.

The spring and summer of 2017 became a turning point when the Russian establishment and the expert community understood the importance of digital technologies for the further development of the country. The most important factor in this shift was the discussion and adoption of the program "Digital Economy of the Russian Federation". At the same time, at the very highest level, a message that "the formation of a digital economy is a matter of national security and independence of Russia, the competitiveness of domestic companies, the country's position on the world stage in the long term, in fact, in decades ahead" was sent.

What is important now is the rise of different initiatives and projects as the result of such high attention at all levels: from national level to the level of individual companies. If such projects turn into a mass phenomenon, there is hope that the number of technological changes will change also the quality of life, management systems, business models, and relationships between people. Only through such complex changes can the Russian economy transform into a digital one.

Only at the end of 2017, there was signed a law which allowed to open accounts and credit lines remotely if the user was authorized in a unified identification and authentication system ("ESIA") and was checked in a unified biometric system ("EBS"). The law was introduced through respective changes in Article 14.1 of the Federal Law No. 149-FZ "On Information, Information Technologies and Information Protection" dated July 27, 2006.

The Government of the Russian Federation has already developed the program "Digital Economy", which stated five basic areas. Among them are the areas related to the creation of basic infrastructure, which also arise the need for special training programs. In addition, McKinsey conducted a comprehensive study in Russia in the last quarter of 2019, which showed the current state of the economy of our country and the areas in which we should move towards the digitalization of the economy [6]. A significant role in the modernization of the legal field concerning the development of the economy digitalization is assigned to the Central Bank, as it should develop a number of regulatory documents based on a qualitative analysis of the global data of the banking market as a whole and provide the transition to a Digital transformation level of thinking in the economic sphere.

But together with the active development of digital transformation, much attention should be paid to the risks that are always present. With active transition to a digital economy, one of the strategic directions of development must become the economic security of the financial sector. Thus, the most sensitive issue, as always, will be the economic security for both the bank and the users of Internet banking and mobile banking applications. Nowadays, the legal vocabulary expended with many names of crimes and offenses related specifically to the Internet environment: carding, phishing, unauthorized access to personal data, fraud through cell phones. Thus, with the active digitalization of the banking sector during the transition to a digital economy, increase in the level of security of credit institutions must become the focus area of development.

In turn, the transition from a cash transaction system to Internet services will result in a shift towards the decentralization of cryptographic systems, which will lead to a redistribution of internal financing of the banking system and will allow to invest additional funds in the development of the bank digitalization. The introduction of open-source software and improvement of its sustainability will significantly reduce the cost of IT for the banking sector of economy. The formation of technology-oriented regulators will result in creation of Internet standards for the banking system managing and will pave the way for further digitalization of the industry. This step will allow to create the possibility of cryptographic identification of the user's identity. The work of banks and other credit organizations will become more transparent, and the user of their services will be able to get even greater confidentiality.

A different kind of risks is associated with the fact that digitalization inevitably erases the boundaries between classical banking itself and non-banking activities, and the speed with which innovative payment instruments occur is much faster than the speed with which banks adapt to them.

\section{CONCLUSION}

A critical condition for the development of the digital economy is to assure all economic entities that the data collected, stored and used are protected from criminal attacks. Ultimately, only the state can provide such 
confidence. To do this, it is necessary to solve several issues: to develop legal norms to respond to cybercrimes, to have qualified cyber police, to develop technological solutions and standards, and to ensure cross-border interaction (as cybercriminals know no boundaries). At the same time, it must be kept in mind that security is secondary to the tasks of development and growth.

\section{REFERENCES}

[1] D. Bell, The Coming of Post-Industrial Society: A Venture in Social Forecasting, Basic Books, 1973, 18 p.

[2] Competing in the digital age (2018) Russia digital economy report. https://openknowledge.worldbank.org Accessed on 10 Jan 2021

[3] R. Dawson (2014) The New Layer of the Economy Enabled by M2M Payments in the Internet of Things. https://www:

rossdawsonblog.com/weblog/archives/2014/09/newlayer-economy-enabled-m2m-payments-internetthings.html Accessed 4 Jan 2021

[4] Yu. V. Kuvayeva, Digital economy: Concepts and Russia's readiness to transition, News of the Ural State University of Economics 20(1) (2019) 25-40. DOI: 10.29141/2073-1019-2019-20-1-3

[5] Alfa-Bank (2016) https://alfabank.ru/press/news/ 2016/12/21/37627.htm Accessed 4 Jan 2021

[6] Discovery research group (2019) Analysis of the market for innovations and new banking products in the field of corporate customer service in Russia and the world//Analytical report https://marketing.rbc.ru/research/29925/ Accessed on 10 Jan 2021

[7] McKinsey \& Company (2018) Innovation in Russia is an inexhaustible source of growth//Research by the Center for the Development of Innovation McKinsey Innovation Practice. https://www.mckinsey.com Accessed 10 Jan 2021

[8] Kremlin (2017) Putin speech at the meeting of the Council for Strategic Development and priority projects. http://www.kremlin.ru/events/president/news/54983

Accessed on 10 Jan 2021

[9] RAEC Digital Economy (2016) Runet Economics Study. http://raec.ru/activity/analytics/9089/ Accessed on 4 Jan 2021

[10] D.I. Stepanova, Digital technologies: a new industrial revolution, The collection: Problems and prospects for the development of industry in Russia, in: Collection of materials of the Second International Scientific and Practical Conference "Enterprises in the
Digital Economy: Risks and Prospects", PRUE, Moscow, 2018, pp. 322-327. 